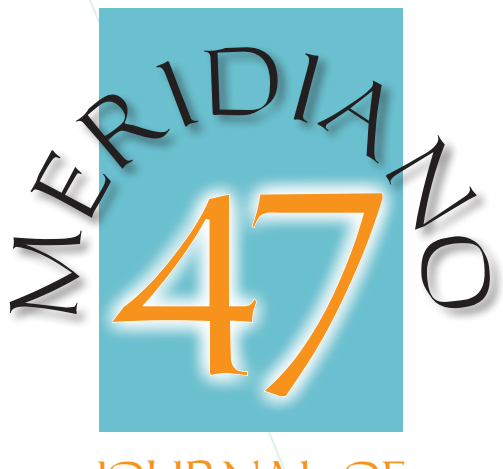

JOURNAL OF

GLOBAL STUIDIES

ISSN 1518-1219

http://www.meridiano47.info

\section{Fernanda Bárbara Lessa Cordeiro}

Universidade de São Paulo, Instituto de Relações Internacionais, São Paulo - SP, Brazil (fernanda.cordeiro@usp.br)

iD ORCID ID:

orcid.org/0000-0001-6016-2886

\section{Natália Dus Poiatti}

Universidade de São Paulo, Instituto de Relações Internacionais, São Paulo - SP, Brazil (npoiatti@usp.br)

iD ORCID ID:

orcid.org/0000-0001-9660-8544

\section{Pedro Feliú}

Universidade de São Paulo, Instituto de Relações Internacionais, São Paulo - SP, Brazil (pedrofeliu@usp.br)

iD ORCID ID: orcid.org/0000-0001-6857-8683

\title{
Polarização Partidária e Política Externa no Reino Unido pré-Brexit
}

\author{
Party Polarization and Foreign Policy in the \\ pre-Brexit UK
}

DOI: http://dx.doi.org/10.20889/M47e21002

Recebido em 13 de novembro de 2019

Aprovado em 5 de março de 2020

\section{Resumo}

No artigo, analisamos o comportamento dos partidos britânicos nas votações de política externa da legislatura anterior à aprovação do referendo do Brexit. Por meio de um modelo geral linear, mostramos que as votações sobre temas relacionados à União Europeia possuem baixa propensão à divergência partidária, enquanto as notícias veiculadas à votação, o desemprego e a relevância da imigração para a opinião pública afetam positivamente o grau de divergência entre os partidos políticos britânicos.

\section{Abstract}

In the article we analyze the behavior of the British parties in the foreign policy votes of the legislature prior to the approval of the Brexit referendum. Through a general linear model, we show that voting on issues related to the European Union has a low propensity for divergence, while news of voting, unemployment and the relevance of immigration to public opinion positively affect the degree of divergence between the British political parties.

Palavras-Chave: Política Externa Britânica, Partidos Políticos, Brexit. Keywords: British Foreign Policy, Political Parties, Brexit.

\section{Introdução}

- This is an open-access article distributed under the terms of a Creative Commons Attribution License, which permits unrestricted use, distribution, and reproduction in any medium, provided that the original author and source are credited.

- Este é um artigo publicado em acesso aberto e distribuído sob os termos da Licença de Atribuição Creative Commons, que permite uso irrestrito, distribuição e reprodução em qualquer meio, desde que o autor e a fonte originais sejam creditados.

\section{c) $\mathbf{O}$}


atual governo Bharatiya Janata Party e o tradicional Indian National Congress assumiu magnitudes bastante elevadas, expressando-se em distintas dimensões como a étnica e religiosa (Varshney, 2014; Vaishnav, 2019). Na Europa, o apoio a partidos políticos radicais em ambos os lados do espectro ideológico é o maior desde os anos 1980 (Foa and Mounk, 2017). Nesse contexto de acirramento da polarização política, o recente evento do Brexit no Reino Unido, em 2016, possui elevado potencial de impacto doméstico e internacional (Maher et al., 2018). Um possível efeito dominó na Europa e as incertezas econômicas e fronteiriças dentro do Reino Unido fazem do Brexit um caso único de grande interesse para o estudo da polarização partidária no palácio de Westminster.

O resultado do referendo sobre a saída do Reino Unido (RU) da União Europeia (UE) não pode ser considerado uma completa surpresa. Desde a entrada do RU em 1973 na UE, os dados de opinião pública apontam o eleitorado britânico como o mais eurocético do continente (Hobolt, 2016). Algumas lideranças do partido Conservador eram ferozmente contrárias à UE, dividindo o partido (De Vries and Edwards, 2009). Referendos sobre a integração europeia são bastante imprevisíveis, pois eleitores geralmente rejeitam a oferta posta pelo governo, mesmo quando os partidos mais tradicionais a apoiam consensualmente (Franklin et al.,1995; Hobolt 2009). Por fim, a mensagem e propaganda populista anti-establishment pela saída foi extremamente efetiva e de rápida dispersão, geralmente alimentada por preocupações sobre imigração, baixas oportunidades econômicas e forte rejeição da classe política (Clark et al., 2017; Rodrik, 2018; Becker et al., 2017).

A opção de deixar a UE não era majoritária entre os principais partidos políticos britânicos, reforçando a relevância da opinião pública no processo, especialmente a pressão exercida sobre o partido Conservador. Entre 2012 e 2013, o Primeiro Ministro David Cameron passou a sofrer forte pressão dos backbenchers eurocéticos de seu partido, aumentando a sua preocupação com a possibilidade do UKIP (United Kingdom Independence Party) roubar votos conservadores, levando-o a propor uma renegociação com a UE (Jensen and Snaith, 2016). O presente estudo analisa fatores políticos, econômicos e midiáticos associados ao grau de divergência dos votos legislativos em política externa na legislatura imediatamente anterior ao Brexit. Para tanto, recolhemos todas as votações nominais sobre política externa entre 2010 e 2014 da Câmara dos Comuns, período do governo de coalizão entre David Cameron e Nick Clegg (líder do Partido Liberal Democrata, indicado Vice Primeiro Ministro). Por meio da estimação de um Modelo Linear Geral (General Linear Model), demonstramos uma associação negativa entre o grau de divergência dos partidos em plenário e os temas relacionados à União Europeia. O resultado confirma a percepção da literatura sobre o consenso partidário em torno da integração europeia, reforçando a relevância da opinião pública em contraposição aos partidos tradicionais no processo decisório que culminou na aprovação do referendo. Quanto maior a preocupação da opinião pública com o tema da imigração, maior a propensão de divergência entre os votos legislativos na Câmara dos Comuns, já indicando na legislatura anterior ao Brexit o forte apelo eleitoral da temática.

Além disso, evidenciamos o efeito positivo da veiculação midiática sobre a matéria legislativa no grau de polarização dos votos. Elevadas taxas de desemprego também afetam positivamente a divergência em plenário, assim como a popularidade do Primeiro Ministro possui um efeito negativo 
no grau de polarização. Temas relacionados à defesa e segurança também tendem a apresentar menor divergência. $\mathrm{O}$ artigo está dividido em quatro partes. Na primeira, revisamos a literatura sobre o comportamento legislativo britânico e a política externa, conferindo especial atenção à campanha do referendo pelo Brexit. Na segunda, descrevemos a metodologia, bem como os dados coletados, as variáveis e respectivas hipóteses de pesquisa. Na terceira, apresentamos os principais achados e, por fim, concluímos o estudo.

\section{Comportamento Legislativo e Política Externa no Reino Unido}

Os votos legislativos na Câmara dos Comuns são fortemente marcados pelo comportamento estratégico do tipo governo versus oposição e elevada disciplina partidária (Baughman, 2004; Kam, 2009; Eggers and Spirling, 2016). Os partidos políticos dominam o processo decisório dos parlamentares, tornando o voto ideológico uma motivação secundária (Hix e Noury, 2016). Roger (2012) sustenta que a disciplina partidária é mantida, sobretudo, pelas etapas que antecedem o processo de tomada de decisão em plenário e o posicionamento a ser adotado é resultado de barganhas, de promessas e de variáveis institucionais, em que as orientações das lideranças são preditivas para o comportamento legislativo. Assim, no voto estratégico, o parlamentar tende a votar junto com a liderança do partido, independentemente de suas preferências ideológicas (Dewan and Spirling, 2011) e os rebeldes contrários à instrução do líder podem sofrer punições e até mesmo expulsão (Spirling e Quinn, 2010). A força das lideranças no parlamento britânico é garantida por meio da oferta ou recusa de acesso a cargos ministeriais e postos de destaque em comissões (Hix e Noury, 2016). Frente ao exposto, a análise da divergência nas votações nominais no parlamento britânico deve ser interpretada em função da oposição entre partidos políticos disciplinados, eventualmente perturbada pela atuação dos backbenchers.

Dada a relevância dos partidos políticos na atuação parlamentar no Reino Unido, é interessante observar na legislatura aqui estudada, 2010-2014, os principais pontos da agenda externa do país em função das preferências partidárias. Beech (2011) sugere que a coalizão de governo entre Conservadores e Liberais Democratas no parlamento britânico protagonizou uma política externa que trazia desafios de um mundo pós-atentados de 11 de setembro e uma opinião pública atenta às questões sobre terrorismo, fundamentalismo islâmico e papel da Grã-Bretanha no sistema de segurança global. Conforme Daddow (2015), a política externa liberal conservadora do Primeiro Ministro David Cameron e do Ministro de Relações Exteriores William Hague buscou constituir consenso em torno de três grandes dilemas: o legado de treze anos dos Trabalhistas, a redução dramática dos recursos econômicos na "era da austeridade" e a reduzida capacidade britânica de exercer influência significativa na comunidade internacional. Onde certamente havia dissenso mais claro era em temas sobre o futuro da União Europeia. Contudo, nesse caso, o Primeiro Ministro estava mais preocupado com seus próprios backbenchers eurocéticos do que com os Liberais Democratas, sugerindo uma situação bastante peculiar em relação ao tradicional domínio das lideranças partidárias sobre o comportamento de seus parlamentares descrito anteriormente. 
O relacionamento do Reino Unido com a União Europeia tem sido uma questão de disputa política antiga (Uberoi, 2015). Conforme mencionado, a Grã-Bretanha aderiu à Comunidade Europeia em 1973 e em 1975, a adesão foi submetida a um referendo, quando 67\% do eleitorado votaram favoravelmente à integração. Em meados dos anos 1990, o UKIP foi fundado, tendo como objetivo a retirada da Grã-Bretanha do bloco europeu. A partir dos resultados das eleições gerais de 2010, dois movimentos políticos protagonizaram a campanha sobre o estabelecimento de um novo referendo sobre a permanência do Reino Unido na União Europeia. De um lado, partidários da saída, composto por grupos anti-União Europeia, entre eles os eurocéticos mais radicais do Partido Conservador, mobilizando a opinião pública sobre temas como imigração e identidade nacional, custos econômicos e soberania britânica, bem como a nova expansão do bloco europeu, com a inclusão de países como Albânia, Montenegro, Sérvia e possivelmente Turquia. Do outro, partidários pela permanência enfatizaram os altos custos financeiros e os grandes riscos econômicos que acompanhariam a decisão pelo Brexit.

De acordo com Clarke et al., (2017), as avaliações de risco e a imagem de líderes proeminentes, como David Cameron, Boris Johnson (membro do Partido Conservador, ex-prefeito de Londres, ex-Ministro de Relações Exteriores de 2016 a 2018 e atual Primeiro Ministro) e Nigel Farage (então líder do UKIP) exerceram influência sobre o resultado do referendo realizado em 23 de junho de 2016, com uma intensa cobertura da mídia sobre os lados opostos assumidos por Cameron e Johnson. Enquanto Cameron mostrou-se partidário à permanência junto ao bloco europeu, por meio da renegociação dos termos do acordo, o comportamento parlamentar de uma parcela dos Conservadores foi marcado por cálculos de carreira (em especial da parte dos backbenchers, pois, em uma possível substituição ao Primeiro Ministro, todos aqueles que endossaram a campanha pela saída poderiam se tornar membros do governo futuramente instituído) e pela preferência pessoal, em que o voto sincero prevaleceu sobre o voto estratégico, em oposição à orientação da liderança (Moore, 2017).

Em outubro de 2011, na votação da moção levantada por uma petição assinada por cem mil britânicos favoráveis à realização da consulta, o governo havia vencido por 483 a 111 votos, no entanto, o resultado produziu, considerando o período pós-guerra, a maior rebelião conservadora à época, uma vez que 81 Conservadores votaram contra a liderança, sendo 49 deles eleitos nas eleições gerais de 2010, o que configurou a maior rebelião backbench desde a formação da coalizão e uma das maiores do partido, em menos de dois anos de governo (Cowley e Stuart, 2012). O texto da moção, de autoria do Conservador David Nuttal, o segundo maior rebelde e também eleito nas eleições gerais de 2010, incluía três alternativas para a questão do referendo, sendo elas a saída, a permanência ou a renegociação. O número de rebeliões dentro do Partido Conservador aumentou consistentemente ao longo dos anos e Cameron já havia sofrido outras rebeliões dessa natureza em temas que envolviam a União Europeia, o que poderia ser indicativo de relativa perda de controle da agenda acrescido pelo descontentamento intrapartidário. Conservadores, leais ao partido quando oposição, esperavam por posições no governo com a eleição de 2010, no entanto, Cameron precisou atender aos interesses dos Liberais Democratas. Além disso, para alguns Conservadores, Cameron não havia sido o vencedor do pleito pela formação de um governo de coalizão, o que acentuou os 
questionamentos quanto à legitimidade da liderança e à lealdade dos demais membros, em particular dos backbenchers (Cowley e Stuart, 2012).

Cameron também teve de lidar com a deserção de dois Conservadores para o UKIP, com o aumento do apoio popular nas eleições para o Parlamento Europeu, realizadas em maio de 2014, quando o partido assegurou 24 das 73 cadeiras (Jeffery et al., (2017). Na tentativa de anular esta ameaça e aplacar o sentimento eurocético em seus próprios backbenchers, Cameron comprometeu-se a realizar o referendo, caso o Partido Conservador fosse vencedor das eleições gerais de 2015. Assim, a campanha pelo referendo sobre a permanência ou saída do Reino Unido da União Europeia expôs não apenas a clivagem interna do Partido Conservador, como também as deserções e traições de parte dos parlamentares integrantes do partido do governo, com atitudes públicas disjuntivas em relação à orientação da liderança. Os eventos descritos tornam a legislatura em questão e o tema de política externa, a partir do ponto de vista do estudo do comportamento legislativo, caso de extremo interesse para a análise da divergência partidária no Reino Unido, tendo em vista a excepcionalidade dos eventos, bem como a sua magnitude em termos de impacto doméstico e internacional.

\section{Metodologia}

A seção de metodologia é composta por duas partes. Na primeira, apresentamos os dados, as variáveis e seus efeitos esperados na divergência legislativa, assim como os critérios de seleção das matérias sobre política externa no Reino Unido. Na segunda, descrevemos o modelo linear geral utilizado na análise estatística, demonstrando a sua adequação em relação aos dados apresentados.

\section{Dados}

A variável dependente da pesquisa é o grau de divergência entre os votos "sim" e "não" de cada uma das 111 votações nominais em temas de política externa entre 2010 e 2014. O uso do voto nominal é um dado muito frequente na literatura especializada nos determinantes do comportamento legislativo (Poole and Rosenthal, 1997). Para classificarmos o tema das votações, utilizamos a ementa da matéria legislativa como parâmetro de seu conteúdo substantivo e para discriminarmos a política externa das demais políticas do Estado, utilizamos a definição de política externa proposta por Tayfur (1994:117): “atividade oficial formulada e implementada por agentes autorizados de um Estado soberano direcionada ao ambiente externo desses Estados". Assim, podemos resumir o conteúdo das votações analisadas em cinco categorias, sendo elas: tratados e acordos internacionais assinados com países estrangeiros e organizações internacionais, política comercial, iniciativas legislativas advindas do parlamento cujo tema é a política exterior, temas de defesa e segurança internacional.

Definida a forma de selecionar as matérias de política externa, geramos como variável dependente o índice de divergência legislativa da seguinte forma: subtraímos a proporção de votos majoritários dos minoritários, para em seguida subtrair essa diferença do valor unitário, como indicado abaixo:

$$
1-\left(\%_{\text {votos majoritários- }} \%_{\text {votos minoritários }}\right)
$$


Assim, em uma votação em que 60\% dos votos foram "sim" e 40\% "não", temos um grau de divergência de 0,8 , em que o índice, cuja variação é de 0 a 1, é crescente na divergência legislativa. As abstenções e ausências em plenário foram descontadas do cálculo.

Descrita a variável dependente do estudo, passamos à descrição de cada variável independente inserida no modelo estatístico:

a) Notícias: um dos principais elos entre o cidadão e a política exterior de um país é a mídia. A difusão de notícias sobre a política internacional é o principal material empírico para conformação de atitudes e preferências da opinião pública em relação ao comportamento do país nessa arena (Soroka, 2003; Willians, 2004; Bevir et al., 2013; Soroka et al., 2012). Como os legisladores estão constantemente atentos às atitudes da opinião pública ao efetuarem o cálculo eleitoral de suas reeleições (Calvo, 2007), em assuntos de política externa, a mídia pode funcionar eficientemente como um mapa dos temas mais relevantes e com maior potencial de impacto eleitoral (Naveh, 2002). Em sistemas de partido único (ou de poucos partidos), quando comparados a sistemas multipartidários, Vliegenthart et al., (2016) sugerem que os partidos de oposição são mais sensíveis à cobertura midiática, pois têm menos informação disponível, uma vez a centralidade decisória no partido do governo. Assim, espera-se que quanto maior a quantidade de notícias sobre determinada votação, maior a chance dos partidos de oposição e possíveis backbenchers rebeldes votarem contra o governo, estabelecendo uma relação positiva com a divergência legislativa. Para determinar a frequência notícias vinculadas ao tema de cada votação, utilizamos o mecanismo de busca da versão digital do jornal The Times, por meio do banco de dados Lexis Nexis Academic ${ }^{1}$. Para tanto, restringimos o intervalo de pesquisa em seis meses anteriores à votação em plenário. Foram coletadas 300 notícias que tratavam sobre temas da política externa britânica para o período do estudo. Soroka (2003) sugere que a cobertura sobre questões internacionais é amplamente encontrada no The Times, quando comparado aos demais jornais do Reino Unido.

b) Popularidade do Primeiro Ministro: um elevado apoio popular do Primeiro Ministro diminui os incentivos dos legisladores a se oporem às medidas do Poder Executivo, em função do elevado custo eleitoral (Rudalevige, 2002). Assim, espera-se que quanto maior a popularidade do primeiro ministro em determinado mês, menor a propensão à divergência legislativa. Inserimos a popularidade do Primeiro Ministro como possível fator aglutinador dos votos legislativos, devido ao poder de agenda-setting centralizado pelo governo e, para construir a variável, foram utilizadas as taxas mensais informadas pelo instituto de pesquisas Ipsos Mori $^{2}$ (que nem sempre coincidem com a votação de um tema sobre a política externa, no entanto, ilustram como a opinião pública avalia o desempenho do Executivo para o período do estudo.

1 Disponível em: http://www.lexisnexis.com/hottopics/Inacademic/ Acesso em 09/11/2019.

2 Disponível em: https://www.ipsos.com/ipsos-mori/en-uk/political-monitor-archive. Acesso em 10/11/2019. 
c) Defesa: Prins e Marshall (2001) argumentam que os temas específicos de defesa nacional e segurança internacional são os temas de política externa que exercem grande influência no comportamento legislativo. Para o caso norte-americano, King (1986) aponta os primeiros, quando comparados à política comercial e ajuda externa, por exemplo, como aqueles com menor grau de consenso entre os partidos políticos. Codificamos como "1" aquelas votações referentes a temas de defesa e " 0 ” as demais temáticas de política externa.

d) União Europeia: Como exposto na seção anterior, os assuntos relativos à União Europeia, por incentivarem atuação rebelde de parlamentares conservadores, possuem elevado potencial de impactar positivamente a divergência legislativa. Assim, identificamos votações sobre legislações, políticas comercial e tarifária e demais elementos que constituem a relação do Reino Unido com o bloco europeu. A variável foi elaborada de forma dicotômica, em que 1 refere-se a temas sobre a União Europeia e 0 aos demais temas da política externa.

e) Desemprego: inserimos na análise uma variável de controle socioeconômica, o desemprego mensal, cujo potencial de impacto positivo na divergência legislativa é bastante significativo (Heinz e Mansfield, 2006). Espera-se que quanto maior o desemprego, maior a divergência legislativa. O índice de desemprego para o período de 2010 a 2014 foi coletado mensalmente por meio dos dados disponibilizados em Trading Economics ${ }^{3}$.

f) Most Important Issue - Foreign Policy (MII-FP): Variável que mede, de acordo com Jennings and Wlezien (2011) como a opinião pública avalia os temas referentes à política externa. Os dados referem-se à porcentagem de britânicos que consideram política externa como o assunto mais importante para o Reino Unido. Espera-se que quanto maior a atenção da opinião pública a assuntos dessa natureza, maior a divergência legislativa, já que os partidos e parlamentares poderiam se beneficiar eleitoralmente ao mostrar opções distintas dos adversários políticos em assunto popular. Os dados foram extraídos de pesquisas mensais realizadas por Ipsos $\mathrm{Mori}^{4}$ através da pergunta "What would you say is the most important issue facing Britain today?", sendo constituídos por respostas espontâneas, ou seja, para as quais não há uma lista predeterminada de opções para os respondentes.

g) Most Important Issue - Immigration (MII-I): essa medida quantifica a porcentagem dos britânicos que considera os assuntos referentes à imigração como os mais importantes para o Reino Unido, de acordo com pesquisa mensal, acima citada, realizada por Ipsos Mori. De acordo com Dennison and Geddes (2019), o aumento da relevância da imigração dentre os assuntos mais importantes para a opinião pública está correlacionada ao aumento da votação em prol de partidos anti-imigração. Espera-se que quanto maior o valor dessa medida, maior a divergência partidária, já que os partidos de direita anti-imigração têm maior respaldo popular.

3 Disponível em: https://tradingeconomics.com/united-kingdom/unemployment-rate. Acesso em 09/11/2019. 
Abaixo indicamos as estatísticas descritivas das variáveis descritas.

Tabela 1. Estatísticas Descritivas

\begin{tabular}{lccccc}
\hline Variável & Média & Desvio-Padrão & Mínimo & Máximo & No de Observações \\
\hline Divergência & 0,47 & 0,36 & 0,01 & 0,98 & 111 \\
F_notícias & 2,70 & 7,10 & 0 & 53 & 111 \\
Defesa & 0,18 & 0,39 & 0 & 1 & 111 \\
UE & 0,66 & 0,48 & 0 & 1 & 111 \\
Popularidade & 39,15 & 5,35 & 31 & 57 & 111 \\
Desemprego & 7,71 & 0,43 & 6,8 & 8,5 & 111 \\
MII-I & 13,46 & 4,43 & 7 & 21 & 111 \\
MII-FP & 2,03 & 1,2 & 1 & 5 & 111 \\
\hline
\end{tabular}

Fonte: elaboração própria dos autores, a partir de dados do Public Whip e The Times, este último por meio da base de dados do Lexis Nexis Academic.

O grau de divergência legislativa possui uma média de 0,47 e um desvio padrão de 0,36. Possui alta variabilidade, tomando o valor 0,01 na votação com menor divergência, muito próximo do valor nulo, menor valor possível do índice, e valor máximo de 0,98 , próximo do valor unitário, maior valor possível do índice por construção. Com relação à frequência de notícias, observamos ainda que há votações para as quais não há notícia alguma, assim como casos que chegam até 53 notícias por votação. Quando verificamos os temas das votações de política externa, 18\% referem-se à defesa nacional, enquanto temas sobre a relação do Reino Unido com a União Europeia a 66\%, o que demonstra a relevância desses tópicos na agenda exterior britânica. A popularidade do Primeiro Ministro também demonstra variação, tomando o valor mínimo de $31 \%$ e o máximo de $57 \%$ de aprovação. As condições macroeconômicas controladas pela variável desemprego apresentam taxas mensais que oscilam entre $6,8 \%$ e $8,5 \%$. Por fim, é interessante observar como a imigração tem relevância em comparação com a política externa na lista de prioridades do eleitorado, que menciona a primeira como a questão mais importante enfrentada pelo Reino Unido em 13,46\% dos casos e a segunda em apenas 2,03\% dos casos, de acordo com o instituto de pesquisas Ipsos Mori.

\section{Modelo}

A escolha do modelo de estimação foi fundamentada em uma característica central da variável dependente: uma variável contínua com limite inferior nulo e superior unitário. Nesta situação, um modelo de regressão linear ignoraria esses limites e, provavelmente, produziria valores previstos inferiores a zero e superiores a um. Nesse caso, poderíamos utilizar um modelo Tobit, um modelo de regressão censurada, que leve em consideração a limitação da variável dependente no intervalo $[0,1]$, e que atribua probabilidades positivas aos extremos do intervalo. Entretanto, como sugerem Papke and Wooldridge (1996), o modelo de regressão censurada não deveria ser aplicado em casos em que 
valores fora do intervalo $[0,1]$ seriam, não somente censurados, como também não observados devido à construção da variável dependente, uma função matemática com imagem dentro desse intervalo. Nesse caso, seria indicada a utilização de um modelo linear geral (GLM - General Linear Model) com uma distribuição binomial e uma função link do tipo logit, nomeado modelo logit fracional.

Gráfico 1. Estimação das curvas de densidade do grau de divergência legislativa

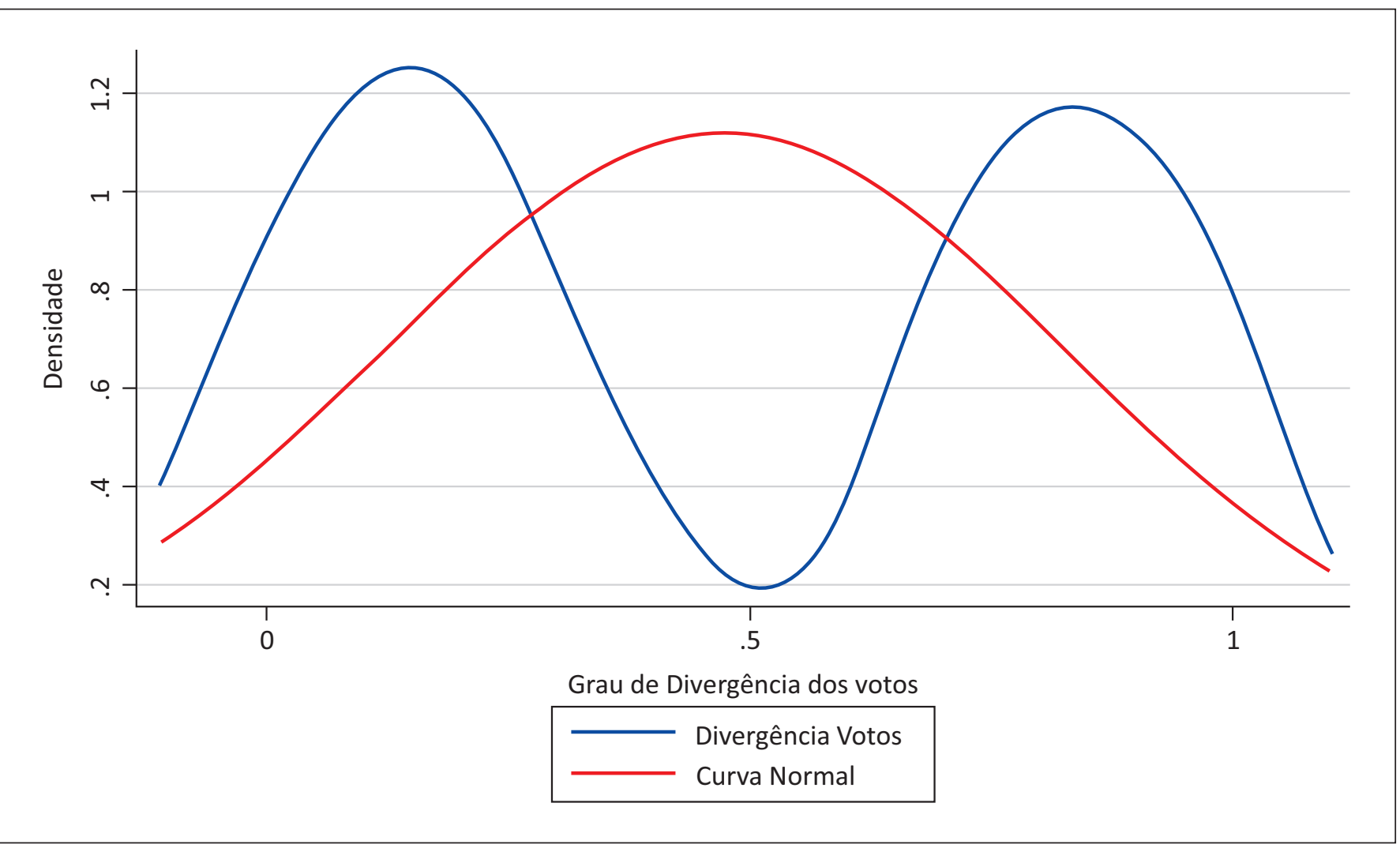

O gráfico 1 permite a observação do comportamento legislativo. Há grande concentração de votos em lados opostos, conferindo aos dados uma distribuição do tipo binomial. Assim, a curva estimada ilustra como os votos dos legisladores polarizam, sendo resultantes da forma em que as votações agrupam-se, de acordo com os temas.

Dado que cada um dos temas de votação pode estar intrinsicamente relacionado às variáveis explicativas incluídas no modelo e influenciar o grau de convergência política, todos os modelos estimados consideraram a presença de efeito-fixo por tema de votação. Por exemplo, se votações sobre a União Europeia estão centradas em temas invariavelmente mais polêmicos, isso levaria a um viés na estimação do impacto da União Europeia no grau de convergência política, objetivo principal do presente estudo. Ademais, determinados temas podem ser considerados invariavelmente mais importantes ou mais frequentemente noticiados, o que levaria a viés na estimação dos parâmetros do modelo. Para realizar a estimação com efeito-fixo, controlamos não somente pela variável defesa, mas também incluímos variáveis binárias para os demais temas de votação, exceto política comercial, definido como grupo de controle. 
Estimamos o modelo logit fracional com efeito-fixo e comparamos os resultados com aquelas provenientes da estimação do modelo Tobit, também com efeito-fixo e limites inferior nulo e superior unitário. Porém, visto que nenhuma votação teve divergência política nula ou unitária, a estimação do modelo Tobit equivale à estimação do modelo linear.

\section{Resultados}

Os resultados das estimações dos modelos de divergência legislativa no plenário da Câmara dos Comuns são reportados na tabela 2. Tanto no modelo GLM, como no modelo Tobit/ Linear, todas as variáveis incluídas são importantes para explicar a divergência legislativa, exceto MII-FP. Juntamente com as estimativas, reportamos o R-quadrado para os dois modelos. Esse R-quadrado foi calculado como sendo equivalente à correlação ao quadrado entre a variável dependente e seu valor previsto pelo modelo. O valor do R-quadrado para o modelo GLM é ligeiramente superior, apesar do modelo GLM não ser estimado através da minimização do somatório dos quadrados dos resíduos, que seria equivalente à maximização do R-quadrado.

Tabela 2. Estimativas dos modelos GLM e Tobit/Linear para a divergência legislativa

\begin{tabular}{lcc}
\hline & GLM & Tobit/Linear \\
\hline F_notícias & $0,04^{* * *}$ & $0,01^{* * *}$ \\
& $(0,01)$ & $(0,01)$ \\
Defesa & $-0,91^{* * *}$ & $-0,21^{* * *}$ \\
& $(0,30)$ & $(0,06)$ \\
EU & $-0,65^{* *}$ & $-0,13^{* *}$ \\
& $(0,31)$ & $(0,06)$ \\
Popularidade & $-0,12^{* * *}$ & $-0,02^{* * *}$ \\
& $(0,02)$ & $(0,01)$ \\
Desemprego & $1,36^{* * *}$ & $0,299^{* * *}$ \\
& $(0,52)$ & $(0,11)$ \\
MII-FP & 0,11 & 0,02 \\
\hline R-quadrado & $(0,17)$ & $(0,04)$ \\
Log-Pseudolikelihood & 0,36 & 0,35 \\
\hline
\end{tabular}

P-valor: ${ }^{*} \mathrm{p}<0.10 * * \mathrm{p}<0.05 \mathrm{e}^{* * *} \mathrm{p}<0.01$.

Erro-padrão robusto (entre parênteses).

Os resultados mostram que a mídia tem um impacto positivo na divergência dos votos dos legisladores. A disseminação de notícias sobre um determinado assunto de votação impacta a percepção dos legisladores sobre a relevância do tema, aumentando a divergência entre os principais partidos políticos britânicos na lógica estratégica de se opor ao governo. As votações referentes à União 
Europeia levam a uma divergência legislativa menor do que as demais. Esse resultado independe dos temas envolvidos nessas votações, visto que foram incluídas variáveis binárias para todos os temas nas estimações, exceto política comercial (grupo de controle). Esse resultado corrobora a tese de que havia uma grande convergência em prol da integração do Reino Unido na União Europeia no contexto da legislatura anterior ao referendo do Brexit. Ao mesmo tempo, a situação econômica estagnada e as altas taxas de desemprego no Reino Unido impactaram diretamente o bem-estar da população e elevado potencial de impactar o comportamento legislativo. De fato, a variável desemprego está associada ao aumento da polarização nas votações. Já a variável defesa leva a uma maior convergência nas votações, resultado esperado dado que as votações sobre política comercial provavelmente têm um impacto mais direto sobre a economia estagnada, estando associada a maior divergência relativa nas votações. Por fim, a popularidade do Primeiro Ministro tem um impacto positivo na convergência de votações, provavelmente devido à sua associação positiva ao custo eleitoral de oposição ao Poder Executivo (Rudalevige, 2002). O impacto marginal médio das variáveis explicativas para o modelo GLM não são equivalentes às estimativas dos parâmetros presentes nessa tabela 2. Por isso, reportamos os impactos marginais médios na Tabela 3 a fim de facilitar a leitura e interpretação.

Tabela 3. Efeitos marginais médios das variáveis explicativas na divergência legislativa

\begin{tabular}{c|c|c}
\hline & Modelo 1: GLM & Modelo 2: Tobit/Linear \\
\hline \multirow{2}{*}{ F_notícias } & $0,01^{* * *}$ & $0,01^{* * *}$ \\
Defesa & $(0,01)$ & $(0,01)$ \\
& $-0,19^{* * *}$ & $-0,21^{* * *}$ \\
EU & $(0,05)$ & $(0,06)$ \\
& $-0,13^{* *}$ & $-0,13^{* *}$ \\
Popularidade & $(0,06)$ & $(0,06)$ \\
& $-0,03^{* * *}$ & $-0,02^{* * *}$ \\
Desemprego & $(0,01)$ & $(0,01)$ \\
& $0,28^{* * *}$ & $0,29^{* * *}$ \\
MII-FP & $(0,10)$ & $(0,11)$ \\
& 0,02 & 0,02 \\
\hline
\end{tabular}

P-valor: $* \mathrm{p}<0.10 * * \mathrm{p}<0.05 \mathrm{e} * * * \mathrm{p}<0.01$.

Erro-padrão robusto (entre parênteses).

Na tabela 3, os resultados mostram que uma notícia adicional aumenta a divergência em um ponto percentual. Em média, as votações sobre a União Europeia têm uma divergência inferior em treze pontos percentuais em relação às demais votações. Esse resultado independe dos temas envolvidos nessas votações, visto que foi utilizado um estimador de efeito-fixo. Ao mesmo tempo, o contexto de estagnação econômica no momento dessas votações e o aumento da polarização política associada ao ambiente econômico desfavorável explicam o impacto significativo da variável desemprego. $\mathrm{O}$ aumento de meio ponto percentual de desemprego, aproximadamente um desvio-padrão dessa 
variável, aumenta a divergência legislativa em quatorze pontos percentuais. Esse impacto é de magnitude similar ao impacto da variável União Europeia, porém de sinal oposto, o que traz indício favorável à hipótese de alta convergência política em assuntos sobre a União Europeia no momento anterior ao referendo do Brexit.

Gráfico 2. Efeito na divergência de votações sobre a União Europeia em relação às demais votações (por níveis de desemprego)

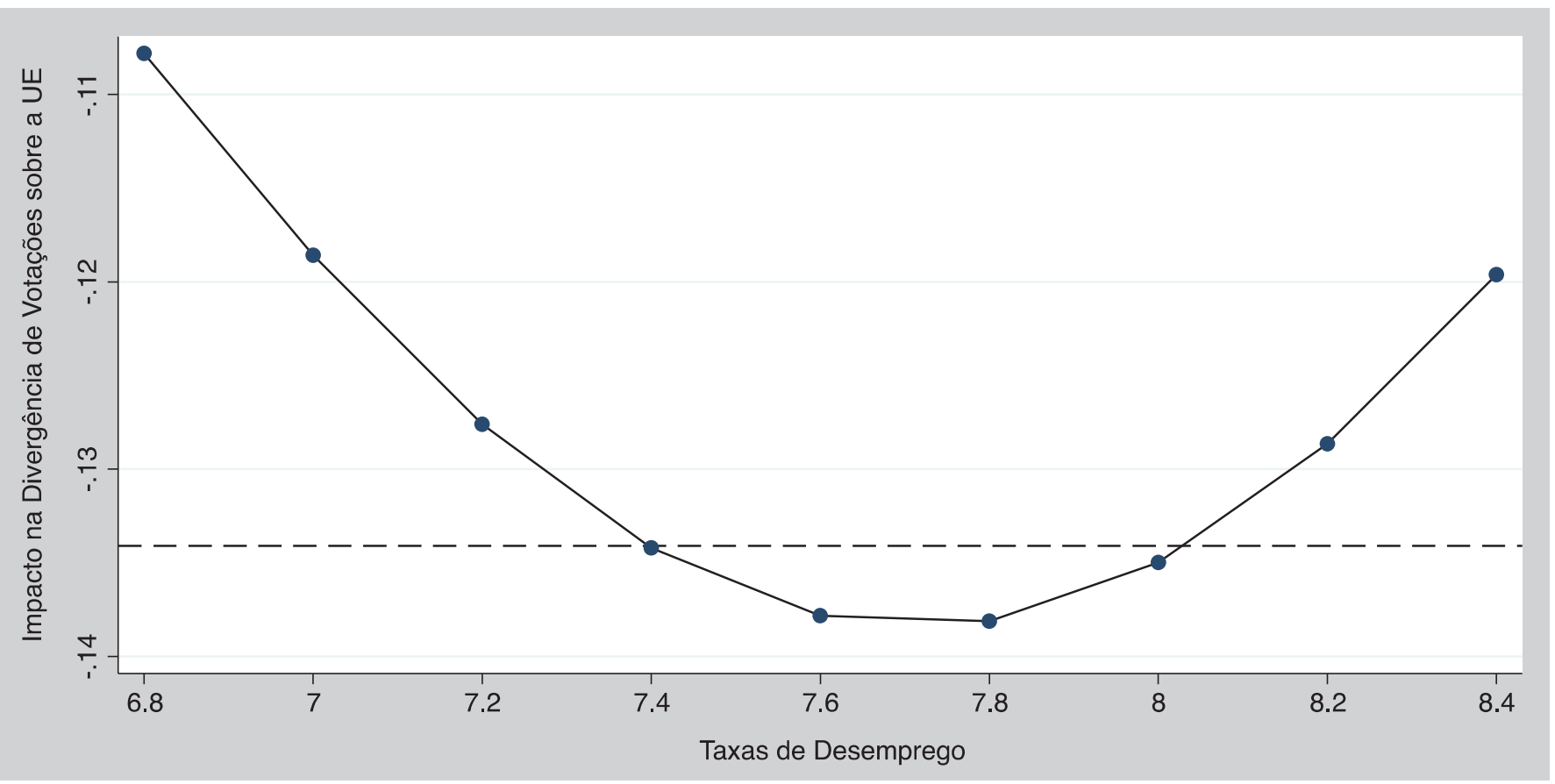

Os impactos marginais médios dos modelos GLM e Tobit/Linear são semelhantes. Porém, o modelo GLM possibilita a estimação de impactos marginais que variam de acordo com os valores das variáveis explicativas incluídas no modelo. O gráfico 2 mostra o impacto na divergência de votações sobre a União Europeia para o modelo Tobit/Linear como sendo equivalente a -.134, independente da taxa de desemprego, e representado pela linha hachurada. Já o impacto para o modelo GLM é superior em magnitude ao impacto gerado pelo modelo Tobit/Linear para níveis de desemprego próximos ao nível médio 7.7 e para a maior parte do tempo (59\% dos dados), representado pela linha cheia. O modelo GLM sugere que, para níveis de desemprego relativamente baixos, as votações sobre a União Europeia apresentam uma divergência legislativa mais próxima às demais votações. Entretanto, para taxas de desemprego mais recorrentes e próximas ao nível de desemprego médio de 7,7, a convergência política de votações sobre a União Europeia é superior em aproximadamente quatorze pontos percentuais em relação às votações sobre outros assuntos.

Para testar a relevância do tema imigratório, muito veiculado durante a campanha pelo referendo Brexit, na legislatura anterior ao mesmo, incluímos a variável Most Important Issue - Immigration (MIII) nas estimações. Os resultados estão reportados na tabela 4. Para as variáveis explicativas incluídas na tabela 3, os impactos marginais são similares, exceto para desemprego, que tem sua relevância aumentada devido a sua correlação com MII-I. Adicionalmente, o aumento de um ponto percentual 
em MII-I leva a um aumento de três pontos percentuais na divergência, mesmo controlando por todos os demais fatores que determinam a divergência política. Dessa forma, o aumento da relevância de assuntos de imigração para a opinião pública está associado ao aumento da divergência política, já indicando qual seria o caminho bem sucedido adotado pela narrativa dos partidários do Brexit (Dennison and Geddes, 2019). Isto é, embora os temas sobre a União Europeia não polarizassem os partidos políticos, a relevância da imigração para a opinião pública incentivou os partidos a se diferenciarem perante o eleitorado, aumentando a divergência entre os mesmos. Além disso, o valor médio de MII-I cresceu nas votações de 2013 e 2014, sendo de 17.06 e 20.80, respectivamente, maior do que a média de 13.46 calculada a partir de todas as votações do banco de dados. Essa análise reforça a relevância crescente da opinião pública no aumento do apoio político a propostas antiimigração que, devidamente aglutinadas às questões europeias, descreve bem o rápido crescimento do sentimento anti-europeu e a consequente ruína do consenso da elite partidária em torno da importância da União Europeia para o Reino Unido.

Tabela 4. Impacto da opinião na divergência legislativa

\begin{tabular}{l|c|c}
\hline & Modelo 1: GLM & Modelo 2: Tobit/Linear \\
\hline \multirow{2}{*}{ F_notícias } & $0,01^{* * *}$ & $0,01^{* * *}$ \\
Defesa \pm & $(0,00)$ & $(0,00)$ \\
& $-0,24^{* * *}$ & $-0,24^{* * *}$ \\
EU & $(0,05)$ & $(0,05)$ \\
& $-0,13^{* *}$ & $-0,13^{* *}$ \\
Popularidade & $(0,05)$ & $(0,05)$ \\
& $-0,03^{* * *}$ & $-0,03^{* * *}$ \\
Desemprego & $(0,00)$ & $(0,01)$ \\
& $\mathbf{0 , 5 3}$ & $\mathbf{0 , 5 5 ^ { * * * }}$ \\
MII-FP & $(\mathbf{0 , 0 7}$ & $(\mathbf{0 , 0 7})$ \\
& 0,04 & 0,03 \\
MII-I & $(0,04)$ & $(0,05)$ \\
& $\mathbf{0 , 0 3}$ & $\mathbf{0 , 0 3 * *}$ \\
\end{tabular}

P-valor: ${ }^{\star} \mathrm{p}<0.10^{\star *} \mathrm{p}<0.05 \mathrm{e}^{\star * \star} \mathrm{p}<0.01$.

Erro-padrão robusto (entre parênteses).

Após realizar a estimação, aplicamos o teste de especificação linktest do STATA para verificar se há indícios de incorreta especificação do modelo. O linktest faz a regressão da variável dependente contra os valores previstos pelo modelo e valores previstos ao quadrado. Se o modelo foi corretamente especificado, os valores previstos ao quadrado não deveriam auxiliar a explicar a variável dependente. De acordo com o linktest, o modelo logit fracional não apresenta problemas de especificação, visto que os valores previstos ao quadrado não tem poder de explicação sobre a variável dependente ${ }^{5}$.

5 Resultados disponíveis sob requisição aos autores. 
Finalmente, o gráfico 3 permite verificar que o aumento da relevância de assuntos sobre a imigração tem impacto maior na divergência quando a popularidade do Primeiro Ministro não é alta e situa-se no intervalo de 35 a 42\% de aprovação. Nos momentos que antecederam a votação a favor do referendo do Brexit, a popularidade média do Primeiro Ministro não foi, de fato, alta, sendo $38 \%$ em 2014.

Gráfico 3. Impacto marginal na divergência de MII-Immigration (por níveis de popularidade do Primeiro Ministro)

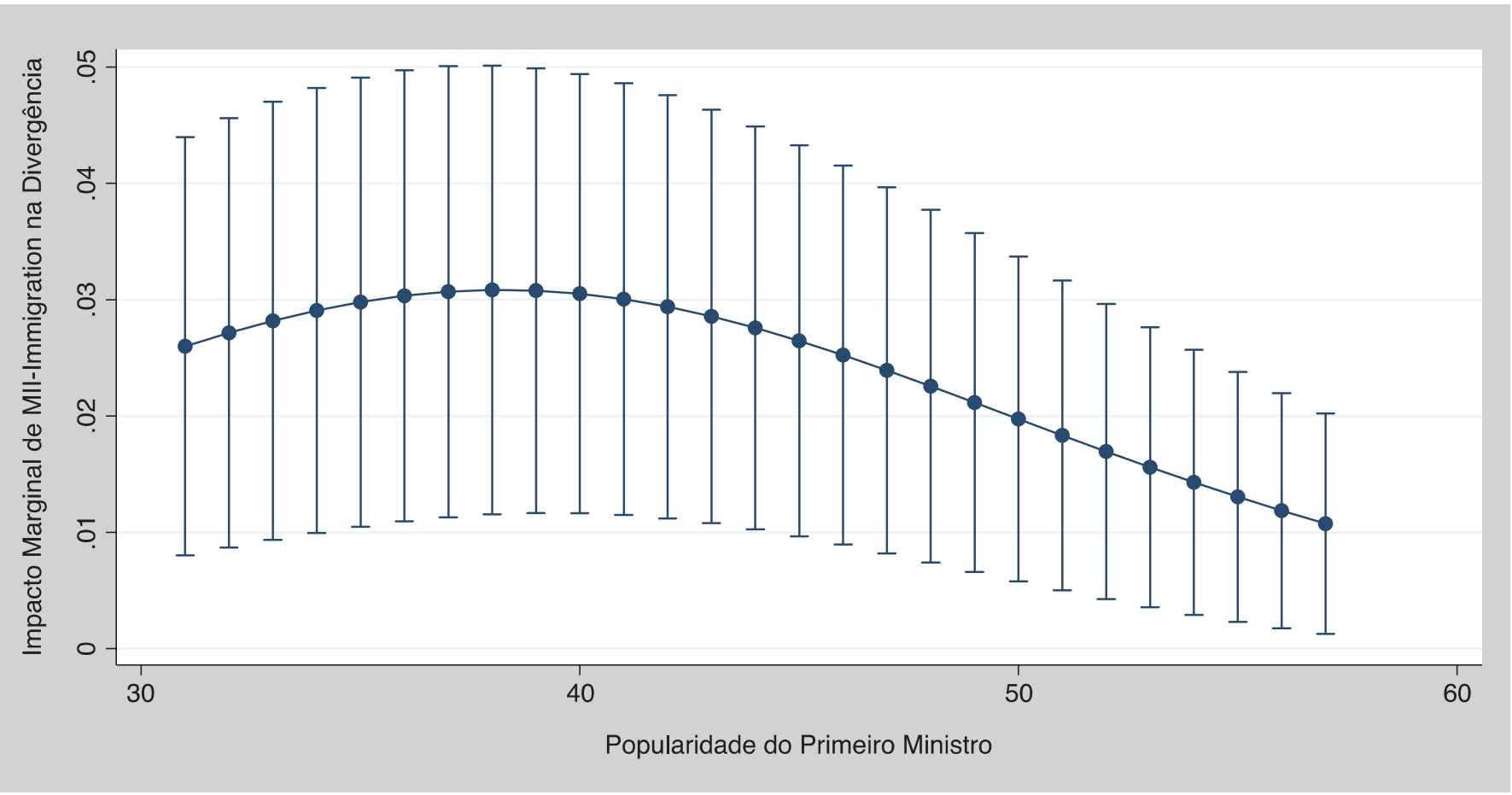

\section{Conclusão}

A literatura especializada sugere que a dicotomia entre governo e oposição é um padrão relevante para se compreender o jogo político no sistema de Westminster, em que a atuação das lideranças partidárias reforça tanto a coesão governamental, quanto a oposição institucional, assegurando o voto estratégico em detrimento ao voto sincero. No entanto, o contexto pré-Brexit começou a alterar essa configuração, sendo marcado pela insatisfação dos backbenchers com o governo de coalizão, o que os levou a questionar a legitimidade da liderança do governo. Embora a atuação dos backbenchers eurocéticos mais radicais exerceu um papel relevante na campanha pelo referendo do Brexit, os resultados exibidos nesta pesquisa demonstram baixa divergência legislativa em torno dos temas europeus na Câmara dos Comuns imediatamente anterior à aprovação do referendo. A ascensão do discurso pró-Brexit veio de fora das fileiras tradicionais dos principais partidos políticos britânicos. As eleições de 2015 modificaram o equilíbrio de forças dentro do partido conservador, premiando uma proporção maior de legisladores eurocéticos. No espaço de um ano, de uma baixa polarização 
nos temas europeus na legislatura 2010-2014, a agenda da política externa britânica foi capturada pela dicotomia pró ou anti Europa. Ainda na legislatura anterior ao Brexit, como os resultados do nosso modelo demostram, a relevância da temática da imigração na opinião pública afetou o grau de divergência partidária, indicando as pistas do conteúdo discursivo com maior potencial de romper a convergência dos principais partidos britânicos a respeito da importância da União Europeia. A decrescente popularidade do primeiro ministro britânico no momento também permitiu o crescimento da contestação da liderança conservadora no interior do partido, abrindo possibilidades para os então backbenchers assumirem protagonismo no partido. Assim, temos a combinação de alguns elementos potencializadores da divergência legislativa na legislatura anterior ao Brexit como o elevado desemprego, a decrescente popularidade do primeiro ministro e uma opinião pública cada vez mais preocupada com a imigração. O que não tínhamos era justamente uma forte divergência nos temas relacionados à União Europeia entre os principais partidos e lideranças do país. A rebelião conservadora após as eleições de 2015 e a conexão da Europa aos fatores propulsores da divergência legislativa na narrativa pela saída do bloco regional auxiliam a entender a rápida ascensão do euroceticismo na elite política do Reino Unido.

\section{Referências Bibliográficas}

Abramowitz, Alan I., Kyle L. Saunders. “Is polarization a myth?” The Journal of Politics 70.2 (2008): 542-555.

Baughman, John. "Party, constituency, and representation: Votes on abortion in the British House of Commons." Public Choice 120(1-2, 2004): 63-85.

Becker, S; Fetzer, T., Novy, D. "Who Voted for Brexit? A Comprehensive District-Level Analysis". Economic Policy, Volume 32, Issue 92, 1 October 2017, Pages 601-650.

Beech, M. “British Conservatism and Foreign Policy: Traditions and Ideas Shaping Cameron's Global View”. British Journal of Politics and International Studies (2011): 1-16.

Bevir, Mark, Daddow, Oliver, Hall, Ian, "Introduction: Interpreting British foreign policy, British Journal of Politics and International Relations, v.15, n.2, (2013): 163-174.

Calvo, Ernesto. “The responsive legislature: Public opinion and law making in a highly disciplined legislature”. British Journal of Political Science, v. 37, n.2 (2007): 263-280.

Clarke, Harold D.; Goodwin, Matthew; Whiteley, Paul. "Why Britain Voted for Brexit: An IndividualLevel Analysis of the 2016 Referendum Vote". Parliamentary Affairs, v.70, n.3 (2017): 439-464. Clinton, Joshua, Simon Jackman, and Douglas Rivers. "The statistical analysis of roll call data." American Political Science Review 98.2 (2004): 355-370.

Cowley, Phillip, Stuart, Mark. "A Coalition with Two Wobbly Wings: Backbench Dissent in the House of Commons”. Political Studies Association, Political Insight (2012):1-11.

Daddow, Oliver. "Constructing a "great" role for Britain in an age of austerity: Interpreting coalition foreign policy, 2010-2015”. International Relations, v.29, n.3 (2015): 303-318. 
Dennison, James; Geddes, Andrew. "A Rising Tide? The Salience of Immigration and the Rise of AntiImmigration Political Parties in Western Europe”. The Political Quarterly, v. 90, n. 1 (2019): 107-116.

De Vries, C.E., Edwards, E. “Taking Europe to Its Extremes: Extremist Parties and Public Euroskepticism”, Party Politics 15(1), (2009): 5-28.

Dewan, T., Spirling, A. "Strategic Opposition and Government Cohesion in Westminster Democracies". American Political Science Review, v.105. n2, (2011): 337-358.

Draca, M., Schwarz, C. "How polarized are citizens? Measuring ideology from the ground-up". Measuring Ideology from the Ground-Up (April 2, 2018): 1-25.

Eggers, Andrew C., Arthur Spirling. "Party cohesion in Westminster systems: inducements, replacement and discipline in the house of commons, 1836-1910.” British Journal of Political Science 46.3 (2016): 567-589.

Franklin, M., Van der Eijk, C. and Marsh, M. "Referendum outcomes and trust in government: Public support for Europe in the wake of Maastricht", West European Politics 18(3) (1995): 101-117.

Foa, Roberto Stefan, Yascha Mounk. “The signs of deconsolidation.” Journal of Democracy 28.1 (2017): 5-15.

Garand, James C. "Income inequality, party polarization, and roll-call voting in the US Senate." The Journal of Politics 72.4 (2010): 1109-1128.

Henisz, W.J., Mansfield, E.D. "Votes and vetoes: The political determinants of commercial openness". International Studies Quarterly, 50(1): 189-211.

Hix, Simon, Noury, Abdul. "Government-opposition or left-right? The institutional determinants of voting in legislatures. Political Science Research and Methods, v.4, n. 2, (2016): 249-273.

Hobolt, Sara. “The Brexit vote: a divided nation, a divided continent”. Journal of European Public Policy, 23(9) (2016): 1259-1277.

Jeffery David, Heppell Tim, Hayton Richard, Crines Andrew. “The Conservative Party Leadership Election of 2016: An Analysis of the Voting Motivations of Conservative Parliamentarians"; Parliamentary Affairs, v.71, n. 2, (2017): 263-282.

Jennings, Will, Wlezien, Christopher. "Distinguishing between most important problems and issues?” Public Opinion Quartely, vol. 75, n.3 (2011): 545-555.

Jensen, Mads Dagnis, Holly Snaith. "When politics prevails: the political economy of a Brexit”. Journal of European Public Policy, 23:9 (2016): 1302-1310.

Kam, Christopher J. Party Discipline and Parliamentary Politics. New York, NY: Cambridge University Press, 2009.

King, Gary. "Political Parties and Foreign Policy: A Structuralist Approach”. Political Psychology, v. 7, n. 1 (1986): 83-101.

Kirkland, Justin H. "Ideological heterogeneity and legislative polarization in the United States." Political Research Quarterly 67.3 (2014): 533-546.

Maher, Paul J., Eric R. Igou, and Wijnand AP van Tilburg. "Brexit, Trump, and the polarizing effect of disillusionment." Social Psychological and Personality Science 9.2 (2018): 205-213.

McCarty, Nolan, Keith T. Poole, Howard Rosenthal. Polarized America: The dance of ideology and unequal riches. MIT Press, 2016. 
McTague, John, Shanna Pearson-Merkowitz. "Voting from the Pew: The Effect of Senators' Religious Identities on Partisan Polarization in the US. S senate." Legislative Studies Quarterly 38.3 (2013): 405-430.

Moore Luke. "Policy, Office and Votes: Conservative MPs and the Brexit Referendum". Parliamentary Affairs, v.71, n.1, (2018): 1-27.

Naveh, Chanan. "The Role of Media in Foreign Policy Decision-Making: A Theoretical Framework". Conflict \& Communication online, v.1, n.2 (2002): 1-14.

Prins, B.C., Marshall, B.W. "Congressional Support of the President: A Comparison of Foreign, Defense, and Domestic Policy Decision Making during and after the Cold War". Presidential Studies Quarterly, v.31, n.4 (2001): 660 - 678.

Poole, Keith T, Rosenthal Howard. Congress: A Political-Economic History of Roll-Call Voting. New York: Oxford University Press, 1997.

Rodrik, Dani. "Populism and the Economics of Globalization." Journal of International Business Policy 1.1-2 (2018): 12-33.

Roger, Léa. "Analyzing parliamentary communication: The impact of role orientations on MEP's discursive behavior in Committee debates". Inaugural General Conference of the ECPR Standing Group on Parliaments, (2012): 24-26.

Rudalevige, Andrew. Managing the President's Program: Presidential Leadership and Legislative Policy Formulation. Princeton: Princeton University Press, 2002.

Soroka, Stuart. N. "Media, public opinion, and foreign policy". The Harvard International Journal of Press/Politics, v. 8, n. 1, (2003): 27-48.

Soroka, S. N., Lawlor, A., Farnsworth, S. y Young, L. Mass Media, and Policymaking. In E. Araral, S. Fritzen, M. Howlett, M. Ramesh and X. Wu (eds.). Routledge Handbook of Public Policy. New York: Routledge, 2012.

Spirlin, A., Quinn, K., "Identifying Intraparty Voting Blocs in the UK House of Commons". Journal of the American Statistical Association, v.105. n.490 (2010): 447-457.

Tayfur, M. F. "Main approaches to the study of foreign policy: A review". METU Studies in Development, 21(1) (1994): 113-141.

Uberoi, Elise. "European Union Referendum Bill 2015-2016. Briefing Paper n. 07212”, House of Commons Library, (2015): 3-32.

Vaishnav, Milna. The BJP in Power: Indian Democracy and Religious Nationalism. Washington, DC: Carnegie Endowment for International Peace, 2019.

Varshney, Ashutosh. "India's Watershed Vote: Hindu Nationalism in Power?" Journal of Democracy 25.4 (2014): 34-45.

Vliegenthart, R.; Walgrave, S.; BaumgartneR, F., Bevan, S.; Breunig, C.; Brouard, S.; Boanfont, L.C.; GrossmaN, E.; JenningS, W.; Mortensen, P.; Palau., A.; Sciarini, P.; Tresch, A. "Do the media set the parliamentary agenda? A comparative study in seven countries. European Journal of Political Research, v.55 (2016): 283-301.

Vliegenthart, Rens, Andreas R. T. Schuck, Hajo G. Boomgaarden, and Claes H. De Vreese. "News Coverage and Support for European Integration 1990-2006”. International Journal of Public Opinion Research 20, (2008): 415-39. 